
ние силумина нанокремнеземом

УДК 539.8

DOI: $18.101 / 2306-2363-2019-2-3-39-44$

\title{
УПРОЧНЕНИЕ СИЛУМИНА НАНОКРЕМНЕЗЕМЕМ
}

\section{(C) А. В. Номоев}

доктор физико-математических наук заведующий лабораторией физики композитных материалов

Институт физического материаловедения СО РАН

670047, Улан-Удэ, ул. Сахьяновой, 6

E-mail: nomoevav@mail.ru

\section{(C) С. В. Калашников}

директор ЦКП

Бурятский государственный университет

670000, Улан-Удэ, ул. Смолина, 24a

E-mail: betch_kail@mail.ru

\section{(C) В. В. Сызранцев}

кандидат физико-математических наук

заместитель директора

Институт физического материаловедения СО РАН

670047, Улан-Удэ, ул. Сахьяновой, 6

E-mail: vveliga@mail.ru

\section{(C) Б. Г. Жалсанов}

аспирант

Институт физического материаловедения СО РАН

670047, Улан-Удэ, ул. Сахьяновой, 6

E-mail: bazarzhap.zhalsanov@mail.ru

\section{(C) В. В. Лыгденов}

аспирант

Институт физического материаловедения СО РАН

670047, Улан-Удэ, ул. Сахьяновой, 6

E-mail: vladimirlygdenov@mail.ru

Рассмотрены аспекты создания упрочненного силумина за счет модифицирования его ультрадисперсными порошками кремния в тонкой магниевой оболочке. Показан механизм повышения адгезии кремния к алюминию обусловленный поверхностноактивными свойствами магния и высокой поверхностной энергии наночастиц, что способствует образованию химических соединений кремния с алюминием, и как следствие, к упрочнению сплава.

Ключевые слова: силумин, упрочнение, энергия Гиббса, наночастицы, наноматериалы, композитные частицы, микрокремнезем

\section{Для цитирования}

Номоев А. В., Калашников С. В., Сызранцев В. В., Жалсанов Б. Г., Льгденов В. Ц. Упрочнение силумина нанокремнеземом // Вестник Бурятского государственного университета. Химия. Физика. 2019. Вып. 2-3. С. 44-51. 
Исследование возможности получения сплавов и композиционных материалов на основе алюминия с использованием аморфного кремнезема является актуальной задачей металлургии цветных металлов. Решение данной задачи дает конкурентное преимущество в металлургической отрасли. Развитие металлургического производства литейных сплавов зависит от себестоимости выпускаемой продукции и возможностей эффективного использования материально-сырьевых ресурсов. Из-за высокой стоимости первичного сырья, которое применяется при производстве алюминий - кремниевых сплавов, важна разработка новых и эффективных способов получения силуминов из отходов кремниевого производства.

С другой стороны, существенна роль упрочнения силумина при модифицировании его нанодисперсным порошком диоксида кремния $[1,2]$, так и с использованием микро- и нанодисперсного кремнезема в процессе производства сплава $[2,3]$.

Рассмотрим возможности упрочнения силумина при введении в расплав кремнезема.

\section{Механизм упрочнения}

Упрочнение алюминиевого сплава достигается, помимо возможных образований частицами зон кристаллизации, увеличением количества химического соединения Al-Si на фоне твердого раствора этих элементов - эвтектики. Но, так как доступным сырьем для цветной металлургии является $\mathrm{SiO}_{2}$, возникает проблема восстановления кремния в расплаве алюминия, которая на сегодня остаётся неразрешённой. Это объясняется высокой химической устойчивостью оксида кремния, обусловленной несмачиваемостью частиц $\mathrm{SiO}_{2}$ жидким алюминием. Несмотря на многочисленные исследования системы $\mathrm{Al}(ж)-\mathrm{SiO}_{2}$, процессы межфазного взаимодействия её компонентов изучены недостаточно полно и представляют значительный научный и практический интерес для установления закономерностей синтеза силуминов, а также изучения структуры и свойств получаемых сплавов [3].

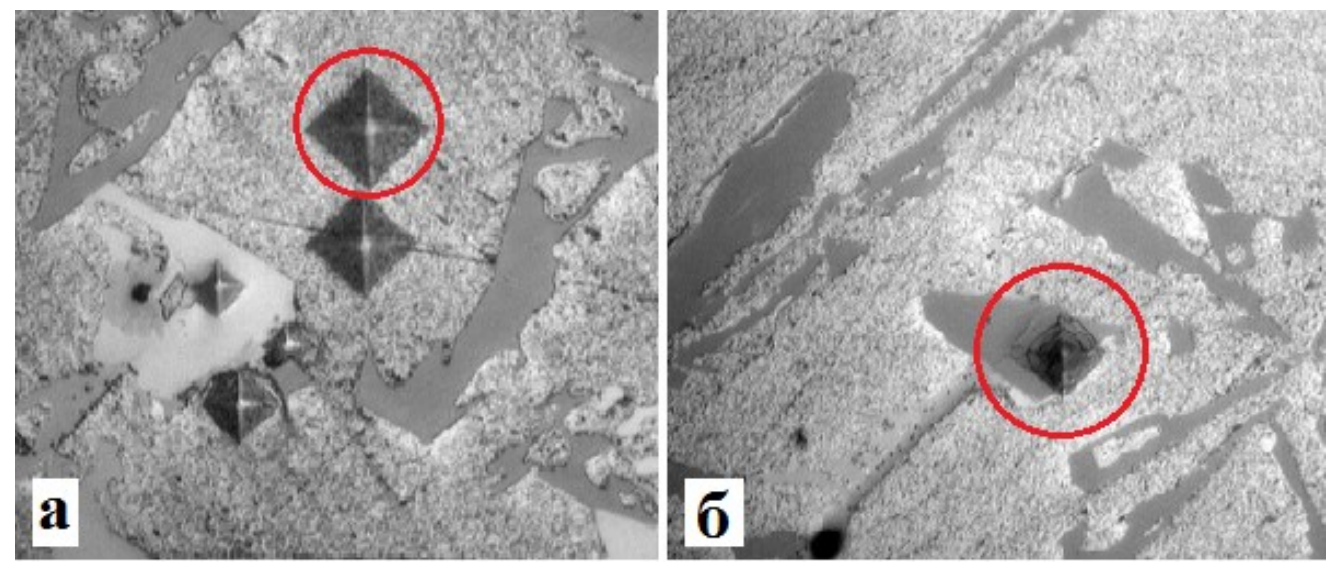

Рис. Размер отпечатка индентора микротвердомера на эвтектике силумина (а) и зерне, являющимся химическим соединением Al-Si (б) 
На рис. 1 представлено полученное авторами микроизображение поверхности заэвтектического силумина на микротвердомере HV-1000. Серые зерна по данным микроэлементного анализа содержат химическое соединение $\mathrm{Al}-\mathrm{Si}$, белое зерно - силициды $(\mathrm{Mn}, \mathrm{Fe})_{\mathrm{m}} \mathrm{Si}_{\mathrm{n}}$, остальное - эвтектика $(\alpha-\mathrm{Al}+\mathrm{Si})[1]$.

На рисунке виден отпечаток индентора микротвердомера, размер его на зерне, содержащим систему $\mathrm{Al}-\mathrm{Si}$ в виде химического соединения (рис. (б)) меньше, чем на эвтектике (рис. (а)), что свидетельствует о больших прочностных свойствах первого.

Поведение примесей алюминия, а также легирующих элементов в процессе получения силуминов с использованием в качестве источника кремния кремнезема $\left(\mathrm{SiO}_{2}\right)$ мало исследовано и представляет значительный интерес применительно к совершенствованию производства алюминиевых сплавов и композиционных материалов.

В работе [3] была установлена термодинамическая возможность протекания реакции восстановления кремния из аморфного кремнезёма алюминием $(4 \mathrm{Al}+$ $3 \mathrm{SiO}_{2} \rightarrow 2 \mathrm{Al}_{2} \mathrm{O}_{3}+3 \mathrm{Si}$ ) в интервале температур 298-1600 К. Следует ожидать протекания данной реакции и при введении наночастиц диоксида кремния в расплав алюминия или силумина. Однако, среди химических соединений, образующихся в системе $\mathrm{Al}-\mathrm{SiO}_{2}$, наибольший интерес с точки зрения влияния на процесс взаимодействия в системе вызывает следующая реакция: $\mathrm{Mg}+\mathrm{SiO}_{2} \rightarrow \mathrm{MgO}$ $+\mathrm{Si}$. Магний в расплаве является легирующим компонентом и эффективным восстановителем кремния, что определяется свободной энергией Гиббса, которая для последний реакции при температуре 1000 К равна -124,27 кДж/моль [3].

Однако в работе [3] не учтен вклад поверхностной энергии микро- или наночастиц в протекание вышеуказанной реакции, который может оказаться существенной причиной упрочнения силумина при введении наночастиц диоксида кремния, полученные в исследованиях $[1,4,6]$.

Оценим поверхностную энергию микро- и наночастиц диоксида кремния. Избыток поверхностной энергии в расчёте на единицу площади раздела фаз характеризуется удельной свободной поверхностной энергией, которая определяется выражением [7]

$$
\frac{\sigma}{\sigma_{\infty}}=\frac{1}{1+h_{a} / r}
$$

где $\sigma$ - удельная свободная поверхностная энергия при кривизне поверхности $\mathrm{r}$; $\sigma_{\infty}-$ удельная свободная поверхностная энергия на плоской поверхности; $h_{a}$ толщина поверхностного (межфазного) слоя [8]. Для наших расчетов толщина данного слоя для частиц диоксида кремния взята из [9].

При малых значениях $\mathrm{r}$ следует воспользоваться формулой Русанова:

$$
\sigma_{\mathrm{H}}=k^{*} r
$$

где $\mathrm{k}^{*}$ - коэффициент, зависящий от свойств контактирующих тел. Однако определение этого коэффициента может быть лишь эмпирическим, что довольно затруднительно [10].

Из формулы (1) можно выразить удельную свободную поверхностную энергию наночастиц: 


$$
\sigma=\frac{\sigma_{\infty}}{1+\frac{h_{a}}{r}} .
$$

На основании формулы (2) рассчитана поверхностная энергия наночастиц диоксида кремния с различным средним размером частиц (табл.), полученных авторами методом разделения в поле центробежных сил [11] и использовавшихся в экспериментальной работе для модифицирования силумина [1].

Большинство наночастиц по отношению к окружающей среде находятся в неравновесном состоянии. Неравновесное состояние означает возможность изменения удельной свободной поверхностной энергии, которая зависит от энергии Гиббса следующим образом

$$
\sigma_{\mathrm{н}}=\sigma+\frac{\Delta G_{\mathrm{T}}}{B_{\text {уд }}},
$$

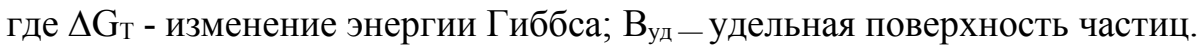

Как видно из табл. удельная поверхностная энергия наночастиц значительно меньше свободной энергии реакции восстановления кремния $4 \mathrm{Al}+3 \mathrm{SiO}_{2} \rightarrow$ $2 \mathrm{Al}_{2} \mathrm{O}_{3}+\mathrm{Si}$, рассчитанной для температур 298-1600 K [3]. Однако, расчет поверхностной энергии для сферических наночастиц с концентрацией 1 мас.\% для одного килограмма силумина дает значения, сравнимые со свободной энергией реакции восстановления кремния.

Таблица Рассчитанная поверхностная энергия наночастиц диоксида кремния с различным

\begin{tabular}{|c|c|c|c|c|}
\hline $\begin{array}{c}\text { Средний } \\
\text { размер } \\
\text { частиц } \\
\text { порошка, } \\
\text { нм }\end{array}$ & $\begin{array}{c}\text { Толщина по- } \\
\text { верхностного } \\
\text { (межфазного) } \\
\text { слоя, нм }\end{array}$ & $\begin{array}{c}\text { Удельная по- } \\
\text { верхностная } \\
\text { энергия на } \\
\text { плоской по- } \\
\text { верхности, } \\
\text { Дж/м² }\end{array}$ & $\begin{array}{c}\text { Удельная } \\
\text { свободная } \\
\text { поверхност- } \\
\text { ная энергия } \\
\text { частиц, Дж/м² }\end{array}$ & $\begin{array}{c}\text { Удельная } \\
\text { поверх- } \\
\text { ность ча- } \\
\text { стиц, м²/г }\end{array}$ \\
\hline 18 & 7 & 0,73 & 0,41 & 140 \\
\hline 24 & 7 & 0,73 & 0,46 & 110 \\
\hline 29 & 7 & 0,73 & 0,49 & 90 \\
\hline 37 & 7 & 0,73 & 0,53 & 74 \\
\hline 50 & 7 & 0,73 & 0,57 & 59 \\
\hline
\end{tabular}
средним размером частиц

\section{Заключение}

Проведенные измерения микротвердости зерен, содержащих силициды и Al$\mathrm{Si}$ показали их высокое значение по сравнению с заэвтектическим соединением $(\alpha-\mathrm{Al}+\mathrm{Si})$. Проведенный расчет поверхностной энергии наночастиц кремнезема с концентрацией 1 мас.\% дает основания предположить высокую эффективность модификации силумина нанокремнеземом.

Работа частично выполнена за счет финансовых средств государственного задания (проект № 01201366187$)$. 
Материаль публикачии подготовлены с использованием оборудования ЦКП «Научные приборы» ФГБОУ ВО «Бурятский государственный университет имени Доржи Банзарова».

\section{Литература}

1. Раднаев А. Р., Калашников С. В., Номоев А. В., Дзидзигури Э. Л. Технологические и прочностные свойства силумина, модифицированного наночастицами диоксида кремния // Металлы. - 2017. - № 1. - С. 37-42.

2. Стацура В. В., Оборин JI. А., Черепанов А. И. и др. Ультрадисперсные порошки в литейном производстве // Ультрадисперсные порошки, наноструктуры, материалы. Мат-лы всерос. науч.- техн. конф. - Красноярск: Сибирский федеральный университет, - 2003. - C. 263.

3. Жалсанов Б. Г. Совершенствование и оптимизация технологических процессов производства цветных металлов: выпускная квалификационная работа (уровень магистратуры): 22.04.02. - ИрНИТУ. — Иркутск, 2018. - 64 с.

4. Стацура В. В., Леонов В. В., Мамина Л. И. и др. Перспективы создания литейных композиционных материалов типа $\mathrm{Al}-\mathrm{Al}_{2} \mathrm{O}_{3}-\mathrm{SiO}_{2} / /$ Литейное производство. - 2003. № 2. - C. 11-12.

5. Курганова Ю. А. Разработка и применение дисперсно-упрочнённых алюмоматричных композиционных материалов в машиностроении: дис. ... д-ра техн. наук. - М. 2008. - 293 с.

6. Анисимов О. В. Технология получения композиционных материалов на основе алюминия, упрочненных дисперсными наночастицами $\mathrm{ZrO}_{2}$ и $\mathrm{SiC}$ в поле центробежных сил центрифуги: дис. ... канд. техн. наук. М. - 2012. - 128 с.

7. Базулев А. Н., Сдобняков Н. Ю. Расчет поверхностного натяжения нанометровых микрочастиц на основе термодинамической теории возмущений // Вестник ТвГУ. Серия: Физика. - 2014. - № 4(6). - С. 140-143.

8. Рехвиашвили С. Ш., Киштикова Е. В. Влияние размерной зависимости поверхностного натяжения на динамику пузырька в жидкости // Журнал технической физики. — 2011. - Т. 81, Вып. 1. - С. 148-152.

9. Сызранцев В. В., Зобов К. В., Самсонов В. М. и др. Присоединенный слой и вязкость наножидкостей // Доклады Академии наук. — 2015. — Т. 460, № 3. - С. 290-292.

10. Сдобняков Н. Ю. Оценка критерия термодинамической стабильности металлических наночастиц с использованием доверительных интервалов для коэффициента пропорциональности в формуле Русанова для поверхностного натяжения // Вестник Новгородского госуниверситета. — 2017. — № 5(103). - С. 43-48.

11. Калашников С. В., Номоев А. В., Дзидзигури Э. Л. и др. Дифференциация наночастиц диоксида кремния по размерам в поле центробежных сил // Российские нанотехнологии. — 2014. - Т. 9(9-10). — С. 52-54.

12. Sobczak N., Jerzy J., Asthana R., Purgert R. The mystery of molten metal // China foundry. - 2010. V. 7(4). - P. 425-437.

13. Арабей А. В., Рафальский И. В. Синтез алюминиево-кремниевых сплавов методом прямого восстановления кремния с использованием алюмоматричных композиционных лигатур // Литье и металлургия. — 2011. — № 3 (61). — С. 19-25.

14. Nomoev A. V., Bardakhanov S. P., Schreiber M. and other. Structure and mechanism of the formation of core-shell nanoparticles obtained through a one-step gas-phase synthesis by electron beam evaporation // Beilstein Journal of Nanotechnology. - 2015. - T. 6, № 1. P. 874-880.

15. Nomoev A. V., Radnaev A. R., Kalashnikov S. V. Nature of diffraction fringes originating in the core of core-shell nanoparticle $\mathrm{Cu} / \mathrm{SiO}_{2}$ and formation mechanism of the structures // Chemical Physics Letters. — 2016. — V. 651. — P. 274-277. 


\section{STRENGTHENING OF SILUMIN WITH NANOSILICON}

A. V. Nomoev

Doctor of Physical and Mathematical Sciences

Head of the laboratory of Physics of Composite Materials

Institute of Physical Materials Science SB RAS

670047, Ulan-Ude, Sakhyanovoy, Str., 6

E-mail: nomoevav@mail.ru

\section{S. V. Kalashnikov}

Director of Core Facilities

Buryat State University

670000, Ulan-Ude, Smolina, Str., 24A

E-mail: betch_kail@mail.ru

V. V. Syzrantsev

Candidate of Physical and Mathematical Sciences

Deputy Director

Institute of Physical Materials Science SB RAS

670047, Ulan-Ude, Sakhyanovoy, Str., 6

E-mail:vveliga@mail.ru

\section{B. G. Zhalsanov}

postgraduate student

Institute of Physical Materials Science SB RAS

670047, Ulan-Ude, Sakhyanovoy, Str., 6

E-mail: bazarzhap.zhalsanov@mail.ru

\section{V. Lygdenov}

postgraduate student

Institute of Physical Materials Science SB RAS

670047, Ulan-Ude, Sakhyanovoy, Str., 6

E-mail: vladimirlygdenov@mail.ru

Aspects of the creation of hardened silumin due to modification with ultrafine powders of silicon oxide are considered. The structure of silumin, consisting of silicide grains, the chemical compound $\mathrm{Al}-\mathrm{Si}$ and the eutectic $(\alpha-\mathrm{Al}+\mathrm{Si})$, has been revealed. The Gibbs free energy and the surface energy of nanosized particles are compared.

Keywords: silumin, hardening, Gibbs energy, nanoparticles, nanomaterials, composite particles, silica fume. 